Esta obra está bajo una Licencia Creative Commons Atribución-NoComercial-Compartirlgual 4.0 Internacional

(c) (1) (8) ()

La inmigración venezolana: análisis de contenido del cibermedio colombiano La Opinión

Herly Alejandra Quiñónez Gómez

Laura España

Keily Rosales

Albymar García

DOI: https://doi.org/10.24215/16696581e185

\title{
La inmigración venezolana: análisis de contenido del cibermedio colombiano La Opinión
}

\author{
Venezuelan immigration: content analysis of the Colombian \\ cybermedia La Opinión
}

\author{
Herly Alejandra Quiñónez Gómez herlyq@gmail.com \\ https://orcid.org/0000-0001-9649-7039 \\ Laura España lauraespana1393@gmail.com \\ Albymar García albymargarcia@gmail.com \\ Keily Rosales keilyr2710@gmail.com \\ Universidad de Los Andes (Venezuela)
}




\section{Resumen}

La inmigración venezolana ha sido representada en múltiples medios de comunicación y en ellos se refleja la crisis humanitaria dentro del país y de aquellos que han decidido salir de él. La Opinión en su cibermedio www.laopinion.com.co ha dado una cobertura periodística constante al ser un medio representativo de la región fronteriza del Departamento Norte de Santander, en Colombia y el estado Táchira en Venezuela. Por ello, esta investigación propone como objetivo general describir el tratamiento periodístico dado a la información sobre el inmigrante venezolano en el cibermedio colombiano La Opinión, mediante un análisis de contenido a la sección Frontera. Entre los resultados destacan: febrero es el mes con mayor frecuencia, las unidades informativas carecen de antetítulo, dominan los títulos informativos y las noticias, gobierno es la fuente más consultada, el tema con más aparición es Sociedad, la etiqueta más empleada es Venezuela, hay uso de hipervínculos internos y existe interactividad. Se concluye que es necesario consultar otras fuentes para darle cobertura al tema, generar otros géneros periodísticos que permitan dar profundidad a la temática y manejar un lenguaje que no atente contra el inmigrante.

Palabras clave: Inmigración venezolana; cibermedio; ciberperiodismo.

\section{Abstract}

Venezuelan immigration has been represented in multiple media and it reflects the humanitarian crisis within the country and those who have decided to leave it. La Opinión in its online media www.laopinion.com.co has given constant coverage as a representative media of the border region of the Norte de Santander Department, in Colombia and the Táchira state in Venezuela. Therefore, this research proposes as a general objective to describe the journalistic treatment given to the information about the Venezuelan immigrant in the Colombian cybermedia La Opinion, by means of a content analysis to the Frontera section. Between the results they emphasize: February is the month with greater frequency, the informative units lack antetítulo, dominate the informative titles and the news, government is the most consulted source, the subject with more appearance is Society, the most used label is Venezuela, there is use of internal hyperlinks and there is interactivity. It is concluded that it is necessary to consult other sources to cover the issue, generate other journalistic genres that allow depth to the subject and handle a language that does not attack the immigrant. 
Key Words: Venezuelan immigration; cybermedia; cyberjournalism.

La migración es parte de la historia de la humanidad y en la actualidad es uno de los eventos noticiosos más importantes en la frontera colombo-venezolana, pues sus efectos han transformado, no sólo la normativa fronteriza, sino que también ha tenido repercusiones económicas, sociales y culturales para ambos países.

En los últimos años, el éxodo venezolano ha ocupado contenido en los medios de comunicación latinoamericanos y mundiales por ser considerado el más alto en la historia de la región.

El diario La Opinión, hace vida periodística en Cúcuta en el Norte de Santander en Colombia en la frontera con el estado Táchira en Venezuela-, siendo este espacio donde este fenómeno ha tenido mayor número de emigrantes, convirtiendo a este país vecino en uno de los principales receptores de quienes huyen de la crisis humanitaria.

De allí que esta investigación estudia la manera cómo el cibermedio colombiano La Opinión informa sobre la inmigración venezolana, ya que precisamente se ubica en la zona más noticiosa, pues norte de Santander es la salida más común de los emigrantes hacia distintas latitudes.

Para cumplir con este objetivo, este texto explica el contexto referencial, los fundamentos teóricos basados en inmigración, frontera, cibermedio y ciberperiodismo, así como la explicación de la metodología y el análisis de los resultados derivados del análisis de contenido de 169 unidades informativas localizadas en la sección Frontera del cibermedio durante ocho meses de 2018.

\section{Contexto referencial}

Colombia y Venezuela comparten una importante herencia histórica desde el nacimiento de ambos países como república. Sus lazos de hermandad se ven reflejados en la similitud de sus culturas, en los colores de su bandera y en su Libertador: Simón Bolívar.

A través de los años se fortaleció el intercambio económico y humano entre ambas naciones, pues se considera que esta frontera era la más dinámica de Latinoamérica, ya que permitió a los ciudadanos de los dos países poder trasladarse sin ningún inconveniente de un lugar a otro. Tal como lo destaca Freitez: 
En el pasado Venezuela fue reconocida por la acogida que brindó a refugiados y asilados provenientes de otros países, particularmente de Colombia en razón de su conflicto armado y de los países latinoamericanos que estuvieron sometidos a regímenes dictatoriales, al punto que entre 1970 y 1980 se contabilizaban en más de 15 mil los extranjeros que habían ingresado al país debido a persecuciones políticas (2011:21).

Robayo (2015) afirma que a partir de la década de los años 70 Venezuela fue receptora de la mayor migración colombiana registrada en el mundo, debido a la bonanza petrolera que demandaba mano de obra y a la situación de violencia reinante en Colombia por la presencia del narcotráfico, crimen organizado y grupos guerrilleros.

Pero esta situación cambió y en la actualidad Venezuela es la nación que atraviesa una crisis económica, política, social y humanitaria. De allí que para el venezolano "emigrar es algo más que la búsqueda de oportunidades económicas, de un trabajo, es también la búsqueda de un contexto seguro que permita el desarrollo de la simple vida cotidiana" (Freitez, 2011: 14).

En los últimos años, el éxodo de los venezolanos ha sido impresionante, ya que se estima que 4 millones de personas viven en el exilio (Michelena, 2018). Los venezolanos optan por destinos latinoamericanos, no muy lejos de su cultura, seleccionando a Colombia porque comparten lazos históricos y culturales y una frontera de más de 2200 kilómetros, lo que facilita la movilidad de las personas, pues suele ser más económico y accesible.

Una investigación liderada por De la Vega y Vargas (2014) revela que para 2014, ya eran 900.000 los venezolanos radicados en dicho país. Por su parte, la Fundación Konrad Adenauer (2018) indica que en 2016 habían migrado 350.000 venezolanos a Colombia, en 2017 el número asciende a 552.000 y en 2018, la cifra se ubica en 1.235 .593 venezolanos residenciados en el país hermano.

Esto se ha convertido en un fenómeno nuevo para la nación neogranadina, ya que pasó de ser un país emisor de inmigrantes a receptor de venezolanos en búsqueda de mejores oportunidades y según Freitez, también para la sociedad venezolana ya que "no tenía la vivencia de la emigración internacional, aquella que implica el abandono del lugar de origen, por un período de tiempo prolongado o indefinido" (2011: 17).

Es así como, esta nueva situación para ambos países, ha encontrado en la prensa una importante ventana para mostrar la crisis humanitaria. Uno de los medios que ofrece una cobertura amplia al tema de la inmigración venezolana, es el cibermedio La Opinión www.laopinión.com.co., el cual nace el 15 de junio de 1960 como diario principal de la ciudad de Cúcuta, norte de Santander en Colombia, luego de haber sido publicado durante 1958 y 
1959 como semanario, de una manera intermitente. Emerge en internet en 1999 y actualmente es el portal web más consultado de la región nortesantandereana (Bermúdez, 2011).

A partir de allí, se plantea la siguiente pregunta de investigación: ¿cómo es el tratamiento periodístico dado a la información sobre el inmigrante venezolano en el cibermedio colombiano La Opinión? Esta investigación se sustenta en Torre (2018), quien analiza en "Periodismo, actores sociales y migración: intertextualidad en los discursos periodísticos sobre migración la intertextualidad" los discursos periodísticos sobre migración en tránsito por el territorio mexicano del periódico El Universal. Concluye que las voces de los actores estatales son las citadas con mayor frecuencia.

Sabés (2010) estudia en Análisis del tratamiento del fenómeno migratorio en www.elpais.com los contenidos del periódico español en su portal web basándose en las temáticas, subtemáticas, referencia, valores y actores. La investigación concluye que en el cibermedio dominan los géneros informativos y la temática relevante consiste en la paz, desarrollo humano, seguridad y legislación.

Otro estudio relacionado con esta investigación es la tesis doctoral titulada Encuadres noticiosos e inmigración: del análisis de los contenidos al estudio de los efectos mediáticos, de Carlos Muñíz (2007), la cual se refiere a los encuadres noticiosos utilizados en los medios españoles, en cuanto a la inmigración latinoamericana y marroquí. Asegura que los medios de comunicación españoles posicionan noticias y encuadres noticiosos que afectan la percepción de la audiencia.

\section{Fundamentos teóricos}

\section{Inmigración y frontera}

En el caso de la inmigración, la Organización Internacional para las Migraciones (OIM) (2006) determina que es el "proceso por el cual personas no nacionales ingresan a un país con el fin de establecerse en él" (p. 36). El término de la inmigración hace referencia al acto de una persona que ingresa a un país diferente al de origen con la finalidad de establecerse allí, bien sea por motivos económicos, académicos o políticos. Por ello, desde el momento cuando el individuo ingresa al país destino se convierte en inmigrante.

Según Migración (2017) existen tres distintas modalidades de migración: migración pendular, regular e irregular, las cuales empezaron a tener relevancia a partir de la apertura de la frontera de forma peatonal en agosto de 2016, tras permanecer un año cerrada. 


\begin{abstract}
La migración pendular es aquella que componen los ciudadanos que residen en zona de frontera y se mueven habitualmente entre los dos países, registrando, incluso, varios ingresos y salidas al día, por un solo Puesto de Control Migratorio. Dicha migración pendular registra un promedio de ingresos diarios de cerca de 36 mil ciudadanos venezolanos y de salidas de casi 34 mil, por los siete (7) Puestos de Control Migratorio habilitados en la frontera entre Colombia y Venezuela (Migración. Ministerio de Relaciones Exteriores, 2017: 5).
\end{abstract}

En el caso de la migración regular "es aquella que ingresa al territorio colombiano con pasaporte por un Puesto de Control Migratorio habilitado, cumpliendo con los requisitos establecidos por la autoridad migratoria" (Ibídem: 6). Mientras que la inmigración irregular, según la Comisión Europea (2012), determina que es la situación en la cual el migrante no cumple con las normas de admisión de un país, su entrada ha sido de manera ilegal o al vencerse su base legal de entrada o residencia carece del estatuto legal requerido para permanecer en él.

Es así como se puede llegar a la conclusión que los conceptos de migración, emigración e inmigración se diferencian en lo siguiente: la migración es el movimiento de la población de su punto de origen a otro con la intención de establecerse en él, la emigración es la acción del individuo al salir de su país de origen y la inmigración es el acto que hace un individuo al ingresar a un país diferente al suyo con la intención de radicarse allí.

Por su parte, el término frontera posee varios significados. Tapia (2012) define frontera basándose en diferentes áreas: para la Antropología la idea de frontera a menudo alude a discontinuidades entre grupos humanos; para la Historia hace referencia a una delimitación territorial y para la Geografía son líneas de demarcación entre unidades que difieren objetiva o subjetivamente.

Las líneas limítrofes son herencias de acuerdos anteriormente establecidos entre los países, las cuales separan a los grupos humanos. Sin embargo, los pueblos de distintos lados comparten una historia que las fronteras no pueden disolver. Una afirmación que respalda Suárez (2015) al determinar que el término frontera tiene una definición compleja, ya que varía según las diferentes disciplinas y posiciones en la que se vea enfocado, como lo son: juristas, militares, empresarios, autoridades nacionales, regionales o locales, campesinos y miembros de comunidades nativas las cuales al estar asociadas a las vivencias cotidianas, herencia y formación cultural pueden establecer las variaciones en el concepto de frontera. 
Sin embargo, existen dos percepciones para entender el fenómeno fronterizo y ellos son: linealidad y zonalidad. En el caso de la linealidad en el contexto de frontera es definido de la siguiente manera:

La linealidad, define a los Estados modernos como entidades espaciales soberanas, de ahí que la necesidad de establecer la cobertura territorial de dicha soberanía postule la linealidad, es decir, el conocimiento preciso de los límites de esa porción de territorio dentro de los cuales el Estado ejerce su jurisdicción (Suárez, 2015: 2).

Entendiendo de esta manera que la linealidad se refiere específicamente a línea limítrofe por donde se pueden llevar a cabo todos los fundamentos jurídicos que se establecen con los tratados internacionales y su ejecución. Además, el concepto de zonalidad en contexto fronterizo al que hace referencia es entendido así:

Frontera se entiende como un término social y económico, en el sentido de constituir la manifestación, en una porción de territorio situado en los confines de un Estado, de fuerzas organizadas que actúan de un lado al otro del límite y cuyos elementos son la población y los acondicionamientos de todo tipo (por ejemplo, senderos, carreteras u otras vías de comunicación; líneas de transmisión de energía eléctrica; explotaciones agrícolas o pecuarias; plantas industriales; centros comerciales, educativos o de salud). Todo lo cual estimula un movimiento e intercambio de personas, bienes y servicios, procesos con base a los cuales se construyen en el tiempo solidaridades e intereses comunes que van perfilando, dentro de ciertos ámbitos espaciales, lo fronterizo (Suárez, 2015: 3).

A partir de estas definiciones, se logra determinar que la frontera puede ser tanto social como económica y que suele sostener una relación de interdependencia en todos los ámbitos que se manejan en las comunidades asentadas en ambos espacios limítrofes de los países que la conforman.

\section{Cibermedio}

La Opinión es un medio impreso que desde hace 20 años tiene su versión digital, el cual reúne los diferentes elementos y características multimedia, hipertextual e interactivas. Para Salaverría (2016) las primeras reflexiones teóricas, en torno a la clasificación de los cibermedios, se centran principalmente en caracterizar a los medios digitales frente a los no 
digitales. Para este propósito perpetúan las mismas bases tipológicas del pasado: el soporte, la periodicidad y, en menor medida, el tema.

Conforme a esta tríada de criterios, un cibermedio es descrito como aquel que -frente a prensa, radio y televisión - se caracteriza por: 1) estar publicado en soporte digital y 2) no estar sometido a periodicidad alguna, puesto que, además de admitir fórmulas de publicación periódica, posibilita tanto la actualización constante de las informaciones (García de Torres y Pou Amérigo, 2003, p. 6972) como su cobertura diferida (Palacios, 2009), lo que convierte de facto al cibermedio en un medio multitemporal (Salaverría, 2016: 23).

Estas son las principales características que permiten diferenciar los medios digitales de los medios tradicionales. Sin embargo es importante mencionar que las tres características consideradas como propias de los cibermedios, no son exclusivas de estos medios.

\begin{abstract}
Nos referimos, en particular, a rasgos como la hipertextualidad, la multimedialidad y la interactividad. Como ya hemos explicado un periódico impreso tiene innegables características hipertextuales (su lectura es no lineal y emplea una arquitectura editorial repleta de remisiones que, en esencia, recuerda mucho a los enlaces hipertextuales), multimedia (su información combina dos códigos lingüísticos: texto e imagen) e, incluso, interactivas (aunque modesta, ¿acaso las cartas al director no son una forma de interactividad?) (Salaverría, 2017: 24).
\end{abstract}

Salaverría (2017) también hace una distinción de los cibermedios entre sí, pues investigaciones recientes apuntan, en efecto, a que los medios digitales netamente periodísticos, no solo muestran una diversidad creciente, sino que se solapan con formas híbridas, para alumbrar lo que ha dado en denominarse metamedios.

Esta distinción consta de nueve criterios propuestos por Salaverría (2017): 1) plataforma (solo para web, solo para tabletas, solo para móviles y multiplataforma), 2) temporalidad (periódicos, de actualización continua y policrónicos), 3) tema (de información general y de información especializada), 4) alcance (internacionales o globales, nacionales, locales, de barrio o hiperlocales), 5) titularidad (de titularidad pública y de titularidad privada) 6) autoría (de autoría individual y de autoría colectiva), 7) enfoque (periodísticos y no periodísticos), 8) finalidad económica (con fines de lucro y sin fines de lucro) y 9) dinamismo (estáticos y dinámicos).

Es necesario conocer estos elementos que engloban el cibermedio y reconocer en primera instancia sus características y sus distinciones más importantes, ya que permite comprender 
con mayor precisión las funciones que cumplen los medios digitales, la estructura y composición del cibermedio La Opinión.

La interfaz del cibermedio analizado en esta investigación contiene todas las características principales del ciberperiodismo (audios, videos, fotografías e interactividad), todos sus componentes audiovisuales e interactivos, que se experimentan en sus diez secciones (Cúcuta, Región, Judicial, Frontera, Actualidad, Opinión, Deportes, Tendencias, Servicios y Participación) y 21 subsecciones.

\section{Marco metodológico}

Esta investigación es mixta, ya que según Hernández, Fernández y Baptista (2014), combina al menos un componente cuantitativo y uno cualitativo en un mismo estudio. Dicho método permite la descripción del tratamiento periodístico de la inmigración venezolana en el cibermedio colombiano de La Opinión.

\section{Análisis de contenido}

El análisis de contenido, según Tinto (2013), es un conjunto de técnicas de análisis de las comunicaciones tendentes a obtener indicadores (cuantitativos o no) por procedimientos sistemáticos y objetivos de descripción del contenido de los mensajes permitiendo la inferencia de conocimientos relativos a las condiciones de producción/recepción (contexto social) de estos mensajes.

Mediante un instrumento de análisis se disecciona el contenido de cada unidad redaccional, donde se emplean las siguientes categorías: fecha, sección, antetítulo, título, sumario, género y naturaleza de la unidad, fuente, tipo y tema de la información, información gráfica, elementos multimedia, hipervínculos, autor e interactividad (Ver tabla 1).

\begin{tabular}{|l|l|}
\hline \multicolumn{1}{|c|}{ Categoría } & \multicolumn{1}{c|}{ Concepto } \\
\hline Fecha & Día cuando se publica el género periodístico \\
\hline Antetítulo & Frase que antecede al titular \\
\hline Titular & Parte principal de la unidad redaccional \\
\hline Sumario & Párrafo siguiente al titular que condensa la información \\
\hline Género & Formas de redacción periodística: noticia, reportaje, entrevista, \\
\hline
\end{tabular}

Question, Vol. 1, N. ${ }^{\circ}$ 63, julio-septiembre 2019. ISSN 1669-6581

Instituto de Investigaciones en Comunicación | Facultad de Periodismo y Comunicación Social | Universidad Nacional de La Plata La Plata | Buenos Aires | Argentina 


\begin{tabular}{|l|l|}
\hline & crónica, reseña, artículo de opinión, editorial y caricatura \\
\hline Naturaleza de la unidad & Informativo, interpretativo, opinión, investigación \\
\hline Fuente & $\begin{array}{l}\text { Personas, documentos o medios de comunicación calificados } \\
\text { para ofrecer información }\end{array}$ \\
\hline $\begin{array}{l}\text { Tipo y tema de la la } \\
\text { información (etiquetas } \\
\text { temáticas) }\end{array}$ & $\begin{array}{l}\text { Base temática. Se establecen los siguientes tipos: salud, } \\
\text { economía, política, sociedad y sucesos }\end{array}$ \\
\hline Información gráfica & $\begin{array}{l}\text { Imágenes: fotografías, gráficos, infografías, ilustraciones, tablas, } \\
\text { caja de datos, mapas }\end{array}$ \\
\hline Multimedialidad & Audio y video \\
\hline Hipertextualidad & Presencia y contenido de enlaces internos y externos \\
\hline Autor & Nombre del periodista o agencia de noticias \\
\hline Interactividad & Posibilidad de emitir comentarios y compartir información \\
\hline
\end{tabular}

Tabla 1. Matriz de contenido del tratamiento de la información (elaboración propia, 2018).

\section{Población y muestra}

La población según Arias (2012), "es un conjunto finito o infinito de elementos con características comunes para los cuales serán extensivas las conclusiones de la investigación. Ésta queda delimitada por el problema y por los objetivos del estudio". En esta investigación, la población son las unidades informativas de la sección Frontera (Imagen 1). Los criterios para seleccionar la muestra son: unidades informativas de la sección Frontera y unidades informativas publicadas a partir del 1 de enero de 2018. El estudio se hizo hasta el 7 de agosto de 2018, ya que durante esa fecha se cumplieron 32 semanas, lo que implica el $60 \%$ del año 2018. 


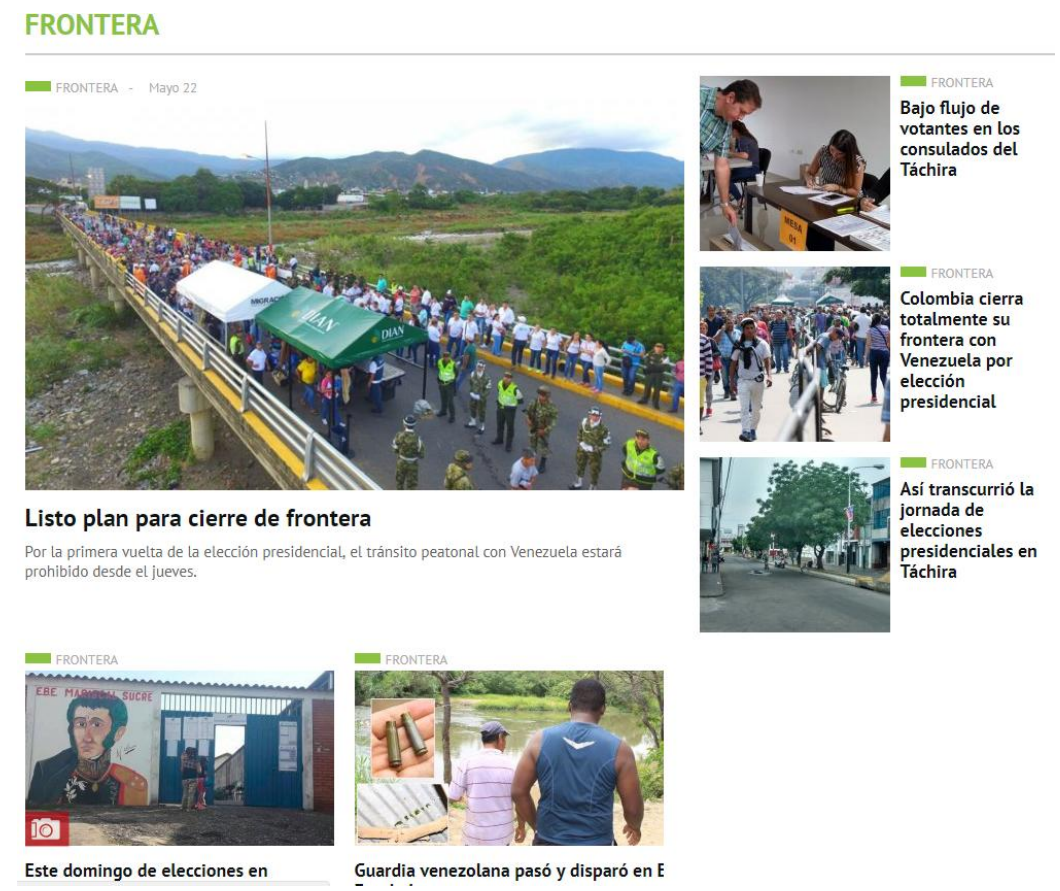

Imagen 1. Sección Frontera del diario La Opinión. Fuente: La Opinión, 2018

\section{Análisis y discusión de los resultados}

\section{- Antetítulo}

En cada una de las 169 unidades analizadas hay ausencia de antetítulo, lo que genera una posible carencia de contextualización en la titulación. Aunque el antetítulo es opcional, su presencia es importante ya que le añade elementos circunstanciales, explicativos 0 referenciales.

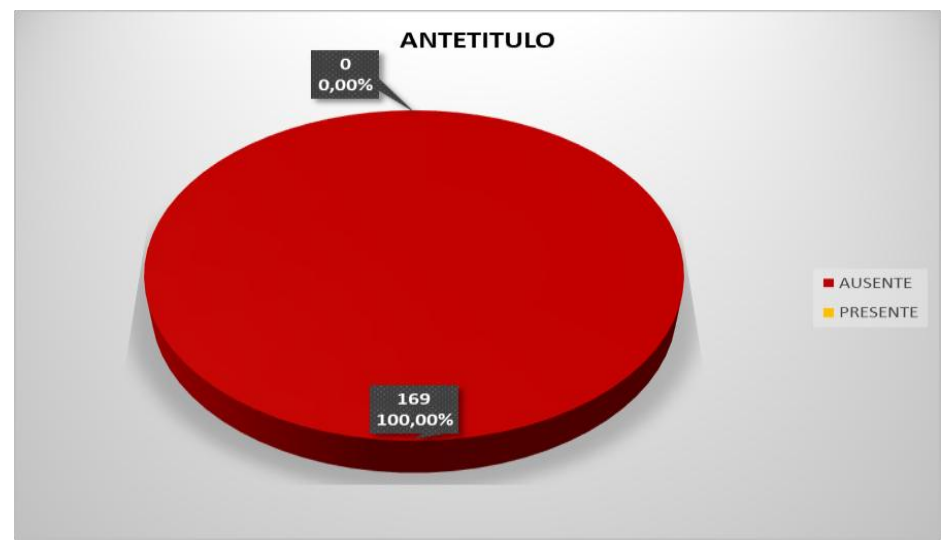


Gráfico 1. Antetítulo. Fuente: elaboración propia, 2018.

\section{- Titulares}

En las unidades informativas existe una notable preponderancia de titulares de tipo informativo con un $65,09 \%$. Otra característica de titulación representada con $22,49 \%$, es la de tipo expresivo, donde se intriga al lector con el uso de preguntas y metáforas como "¿Qué tanto sufre un niño venezolano que llega a estudiar a Colombia?" y "La Parada: ni en la calle hay cama pa' tanta gente de Venezuela", los cuales buscan atraer la atención del lector.

De igual manera recurren a la titulación del acto de habla, donde se usa una cita textual para vincular e indicar al lector desde el inicio de la unidad redaccional, quién será la fuente informativa principal. Con este aspecto hay 21 unidades que componen un $12,43 \%$ de la muestra.

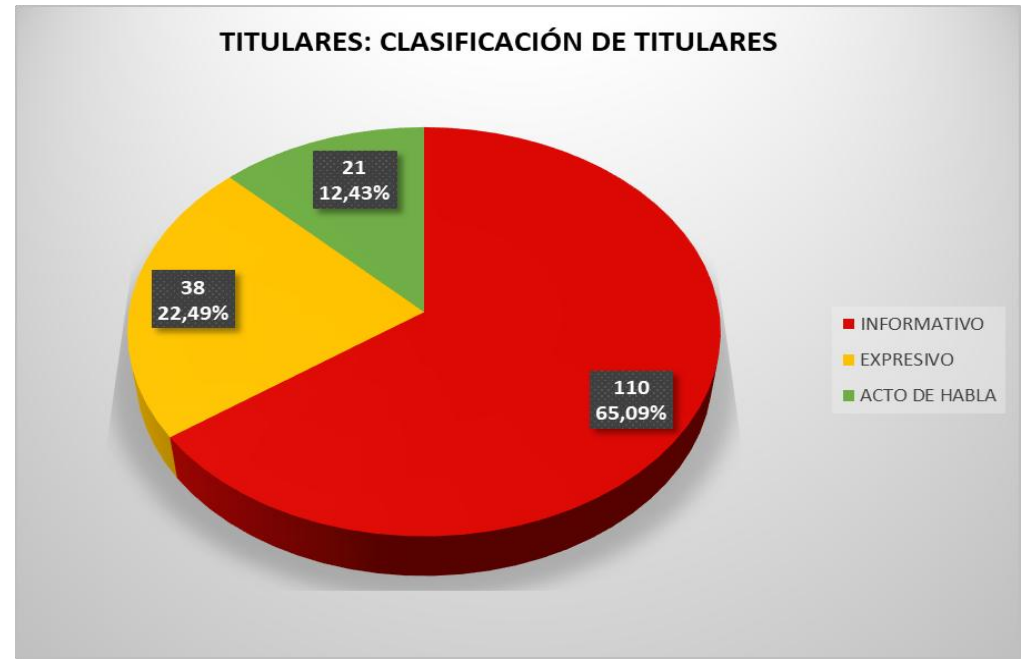

Gráfico 2. Titulares. Fuente: elaboración propia, 2018.

\section{- Sumario}

El sumario está presente en todos los géneros periodísticos, quedando claro que para dicho diario es necesaria la presencia de este elemento, pues condensa la información más importante. Esto con el objetivo de atraer la atención del lector y de esta forma, muestre interés por leer el texto completo. 


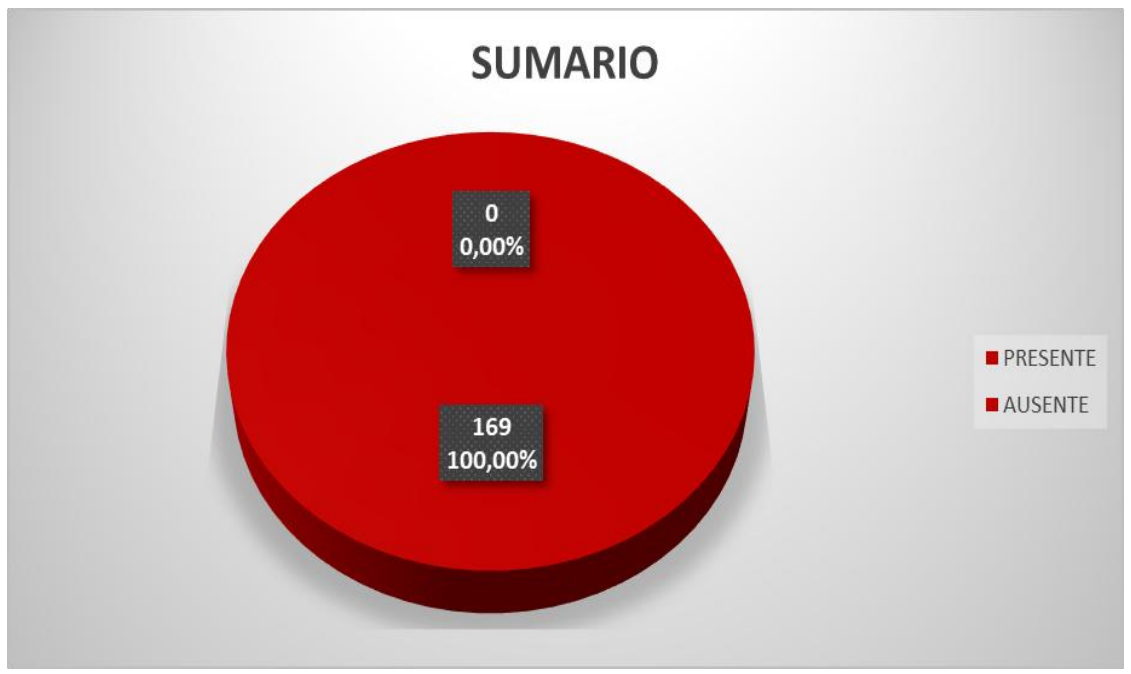

Gráfico 4. Sumario. Fuente: elaboración propia, 2018.

\section{- Géneros periodísticos}

El género más destacado es la noticia, con 139 unidades redaccionales $(82,25 \%)$. La noticia es el género más frecuente para difundir información y en el caso de movimientos migratorios, es común que sus apariciones incrementen por la sencillez de su contenido y su inmediatez.

La Opinión deja poco espacio para el reportaje, con apenas 21 unidades redaccionales $(12,43 \%)$, siendo uno de los géneros que permite explicar detalles con interés colectivo. Por otro lado, con cinco $(2,96 \%)$ unidades, se encontró la crónica para narrar historias de vida. Los artículos de opinión se llevaron escasamente una porción de 1,78\%. En uno de los casos, el diario compartió una vídeo columna del medio colombiano El Espectador, llamada "Las Igualadas", donde hablan sobre temas de género y en esa oportunidad estuvieron en la frontera explicando "Lo peor de ser venezolana en Colombia", donde se explican las dificultades por las cuales atraviesan las inmigrantes en la ciudad de Cúcuta por ser mujeres. Con sólo una entrevista, la fuente informa sobre la situación de Venezuela, la cual es comparable a los procesos de devastación que producen las guerras. 


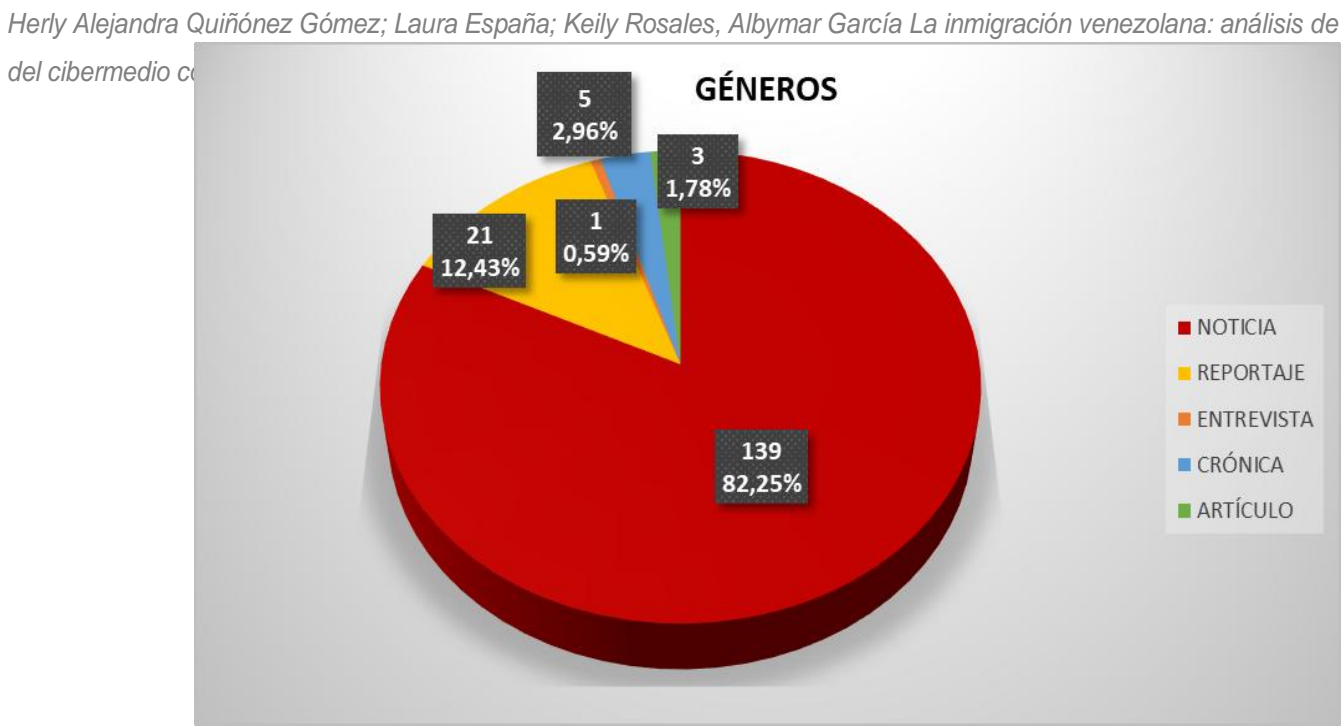

Gráfico 4. Géneros periodísticos. Fuente: elaboración propia, 2018.

\section{- $\quad$ Naturaleza de la información}

Con la mayoría de las unidades redaccionales a su favor, la naturaleza informativa se posiciona con el $85,21 \%$ del total. El segundo puesto se lo queda la interpretación, con un porcentaje de $13,02 \%$, la cual fue presentada en forma de reportaje, explicando de manera amplia y detallada las dificultades para cruzar la frontera de manera legal.

Por otro lado, la opinión ocupa el siguiente puesto, con dos artículos, equivalentes a una porción del 1,18\% y el último puesto, con una pequeña parte, se lo lleva la investigación con una sola unidad redaccional a su favor representando el 0,59\%, presentado en forma de entrevista, donde la fuente proporciona datos precisos sobre la cantidad de migrantes venezolanos y su desenvolvimiento en territorio colombiano.

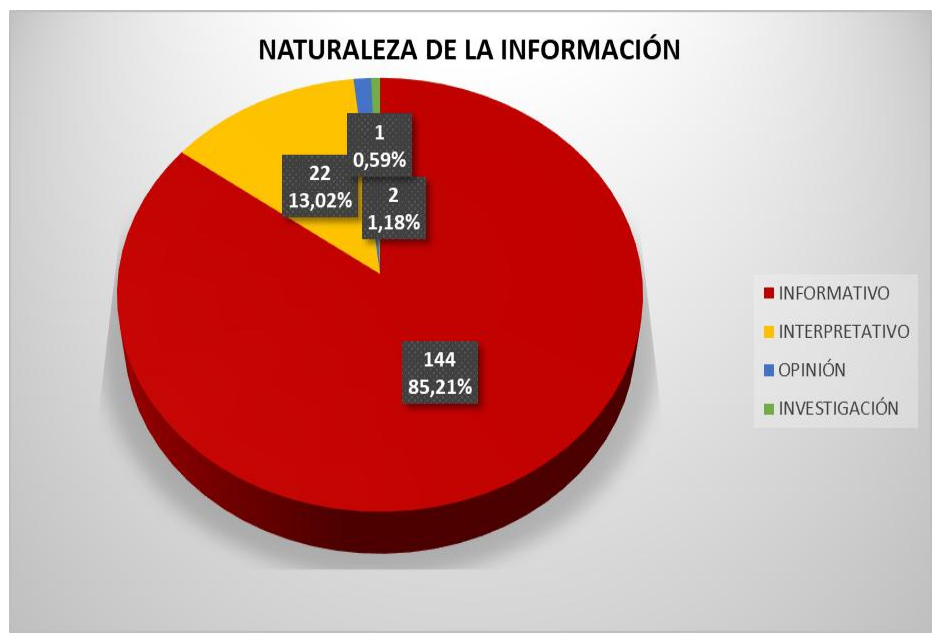

Gráfico 6. Naturaleza de la información. Fuente: elaboración propia, 2018. 


\section{- Fuentes}

El cibermedio La Opinión con 43,70\% demuestra el uso frecuente de fuentes gubernamentales. De igual manera se encuentran porcentajes de fuentes como un 23,95\% particulares, especialistas $4,94 \%$, documentales $5,43 \%$, instituto $7,90 \%$, militares $5,93 \%$, universidades $3,46 \%$, ONG 3,70\% y agencia periodísticas $0,99 \%$.

Es importante destacar que la representación de fuentes gubernamentales fueron las más utilizadas, con 177 fuentes gubernamentales, entre las cuales se encuentra Migración Colombia, cancilleres, presidentes, concejales, gobernadores entre otros, constituyendo un $43,70 \%$.

Además, la existencia de las fuentes particulares son 97 en las 169 unidades informativas analizadas, representando así un $23,95 \%$, los cuales respaldan esta fuente en entrevistas, reportajes y noticias que recoge declaraciones comúnmente de personas que transitan diariamente en la frontera colombo-venezolana.

En el caso de las fuentes militares, el medio hace uso de 24, representando un 5,93\%. Esto es comprensible debido a la temática de migración y frontera que diariamente amerita la presencia militar en estos aspectos. Asimismo, se ven representados con un rango porcentual similar fuentes como las documentales quienes cubren un 5,43\%, especialistas un 4,94\%, ONG con $3,70 \%$, universidades con $3,46 \%$. Sin embargo, se pudo observar un rango aún menor en el uso de fuentes como lo son las agencias periodísticas, con tan solo 4 fuentes, representando un $0,99 \%$.

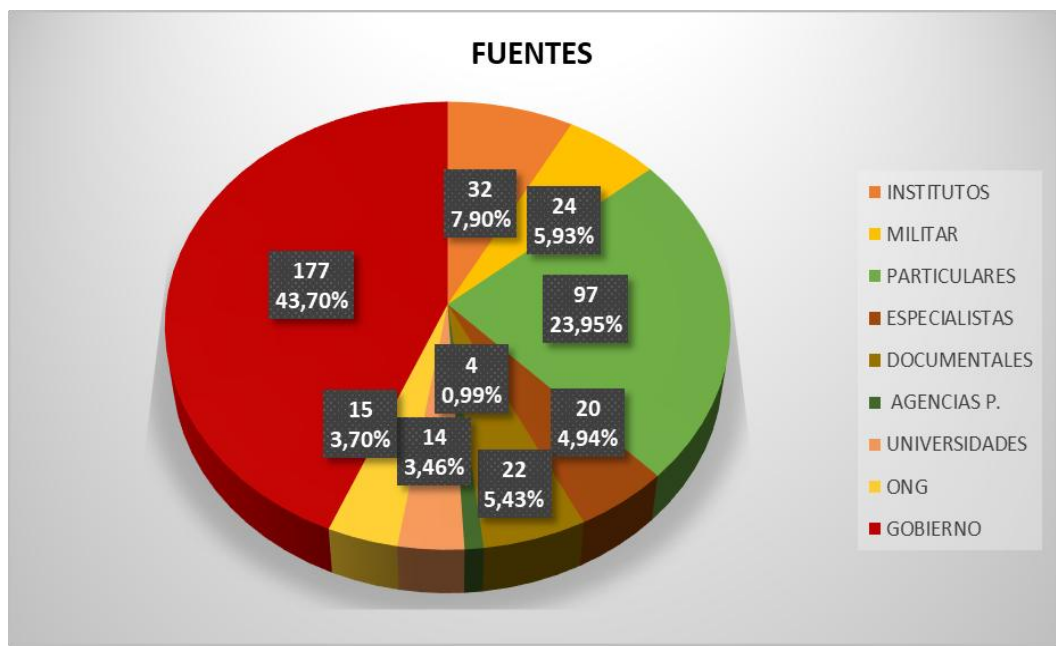

Gráfico 7. Fuentes. Fuente: elaboración propia, 2018. 


\section{- Temática}

Con $63,89 \%$ (115) la temática de sociedad destaca dentro de la información presentada en cada una de las unidades. Allí se observan las dificultades e incomodidades del venezolano. También resaltan las numerosas ayudas sociales que brindan distintas organizaciones gubernamentales y no gubernamentales.

Seguidamente, se encuentran las informaciones de salud con 26 apariciones, ocupando un porcentaje de $14,44 \%$. Es normal que esto suceda, ya que la mayoría de las personas emigran con la finalidad de cubrir las necesidades hospitalarias. Esta situación fue constantemente explicada en varias unidades redaccionales, así como la implantación de rigurosos controles epidemiológicos para la prevención de pandemias provenientes de Venezuela.

El tercer lugar lo ocupa la fuente política con un $11,67 \%$, demostrando las tensiones políticas entre Venezuela y Colombia y las diferencias entre sus presidentes. En la posición número cuatro se estableció la fuente de economía con 11 (6,11\%) muestras encontradas a su favor, resaltando variedad de temas como: el comercio y los tratados binacional, el diferencial cambiario y el poco poder adquisitivo del venezolano.

El último lugar, se lo lleva la temática sucesos con un 3,89\% (7 notas periodísticas en total), destacando los conflictos entre bandas que operan en los pasos fronterizos ilegales, el incremento de robo, hurtos y asesinatos en la ciudad Cúcuta y sus alrededores, en la mayoría de estos casos las víctimas y los implicados en estos delitos son personas con nacionalidad venezolana.

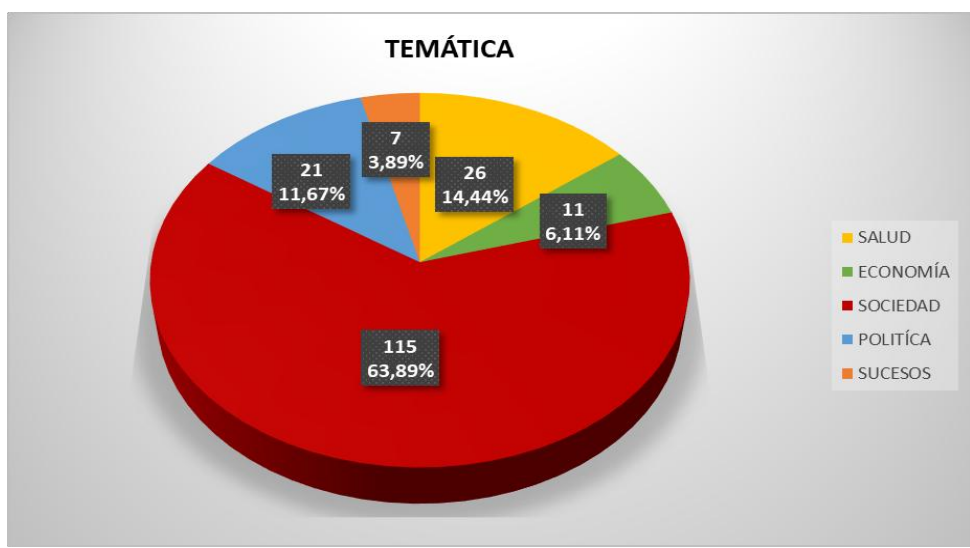

Gráfico 8. Temática. Fuente: elaboración propia, 2018.

\section{- Presencia de etiquetas}

Como se puede observar en los resultados obtenidos en el conteo realizado, para el cibermedio es de gran importancia la incorporación de etiquetas dentro sus unidades 
redaccionales ya que se encuentran presentes en un 99,41\% (168), dejando sólo un artículo informativo con ausencia de etiquetas (0,59\%).

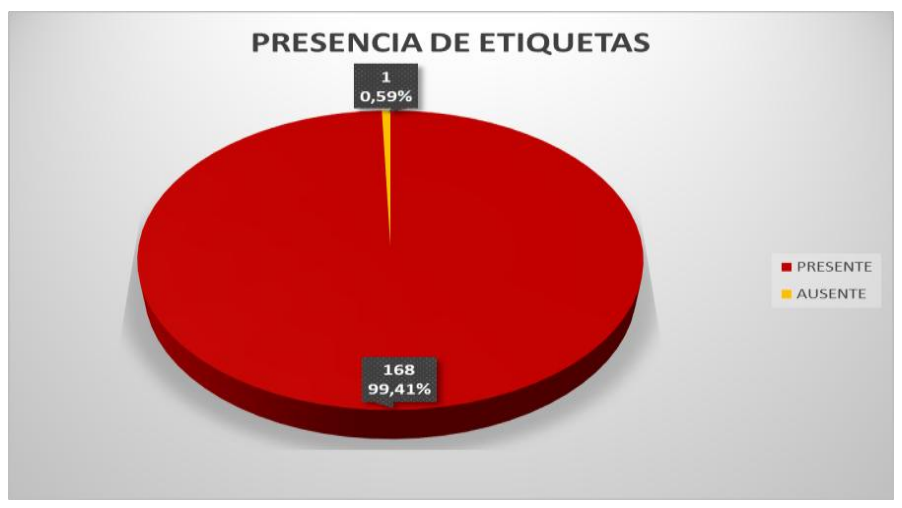

Gráfico 9. Presencia de etiquetas. Fuente: elaboración propia, 2018.

\section{- Tipos de etiquetas}

Hay que explicar que el cibermedio utiliza variedad de etiquetas en cada uno de sus géneros periodísticos. Estas son usadas dependiendo del tema tratado, por lo tanto las etiquetas varían en número y en tema, lo que significa que no se consiguen siempre las mismas. En esta investigación se analizan seis etiquetas. Estas fueron seleccionadas debido a la frecuencia con que aparecen.

La etiqueta "Venezuela" se lleva la porción más grande de los resultados con un porcentaje de $32,21 \%$, seguida de "venezolanos", con un $12,43 \%$, en tercer lugar aparece a "crisis", la cual le corresponde el $17,45 \%$. En el cuarto, quinto y sexto puesto figuran "Colombia" con 12,4\%, "frontera" con $11,07 \%$ e "inmigrantes" con $4,70 \%$.

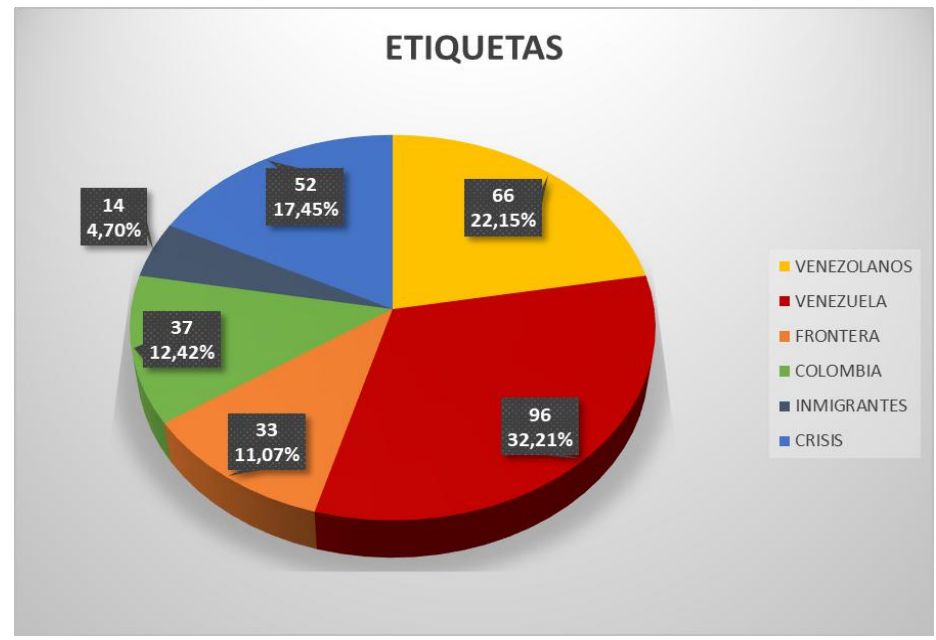

Gráfico 10. Tipos de etiquetas. Fuente: elaboración propia, 2018.

Question, Vol. 1, N. ${ }^{\circ} 63$, julio-septiembre 2019. ISSN 1669-6581

Instituto de Investigaciones en Comunicación | Facultad de Periodismo y Comunicación Social | Universidad Nacional de La Plata La Plata | Buenos Aires | Argentina 
Herly Alejandra Quiñónez Gómez; Laura España; Keily Rosales, Albymar García La inmigración venezolana: análisis de contenido del cibermedio colombiano La Opinión

\section{- Información gráfica}

El portal web presenta un $96,86 \%$ de información gráfica con el uso de fotografías y un $3 \%$ de infografías. Aparecen 216 fotografías en las 169 unidades informativas analizadas. Este cibermedio recurre al uso de fotografías captadas por sus lectores. Cada fotografía cuenta con una leyenda que describe el suceso así como al autor de la fotografía.

Asimismo, se encontró el uso de infografías (7) con referencia a la totalidad de unidades informativas analizadas, haciendo más explicativo mediante cifras los fenómenos como la migración, problemas sociales, la escolaridad, entre otros.

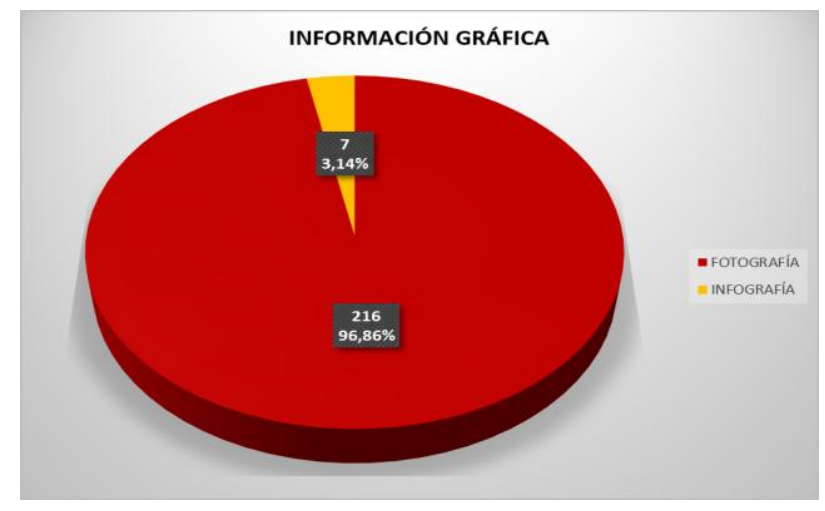

Gráfico 11. Información gráfica. Fuente: elaboración propia, 2018.

\section{- Multimedialidad}

En las unidades, se ven representados con un $92,86 \%$ el uso de videos y un $7,14 \%$ el uso de audios. El uso de 13 videos y un solo audio en las 169 unidades informativas, denota que el medio recurre en pocas ocasiones al uso de la herramienta de multimedia.

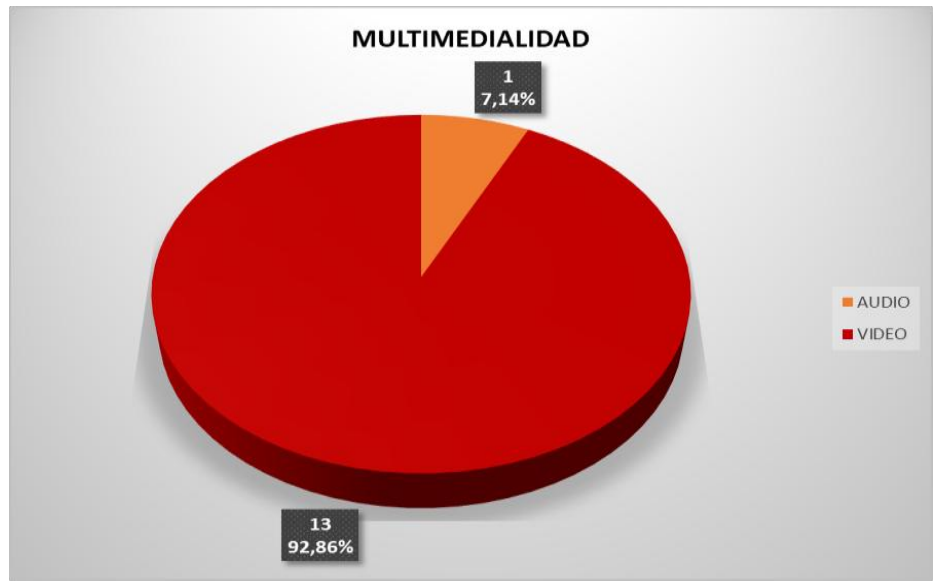

Gráfico 12. Multimedialidad. Fuente: elaboración propia, 2018. 
Herly Alejandra Quiñónez Gómez; Laura España; Keily Rosales, Albymar García La inmigración venezolana: análisis de contenido del cibermedio colombiano La Opinión

\section{- Hipertextualidad: Presencia de hipervínculos}

El cibermedio no es ajeno al uso de la hipertextualidad, haciendo partícipe al usuario de una retroalimentación necesaria con un fenómeno como la inmigración venezolana. En el 55,03\% de las unidades analizadas existe la presencia de elementos hipertextuales que se unifican tanto de manera interna, en el mismo portal web, como de manera externa a éste.

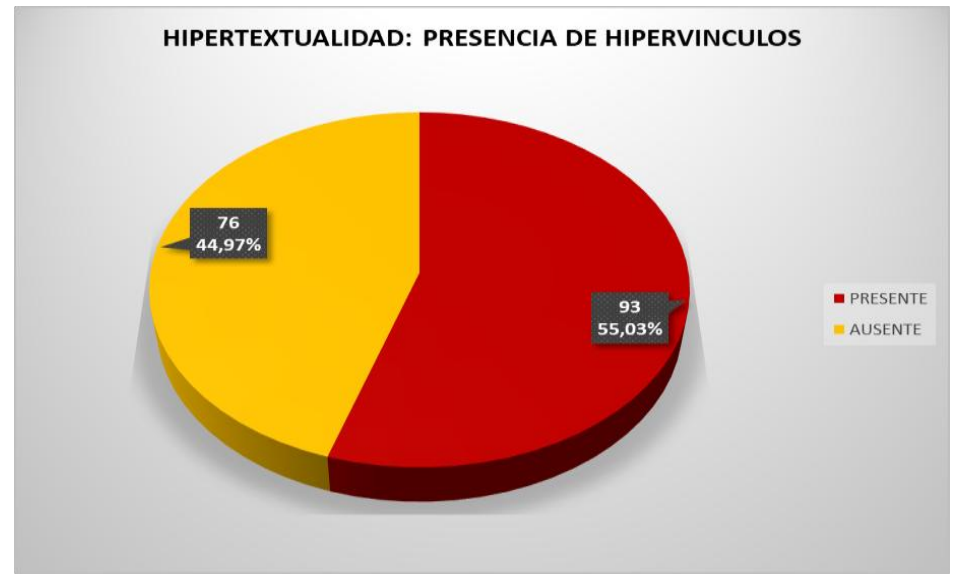

Gráfico 13. Hipertextualidad: presencia de hipervínculos. Fuente: elaboración propia, 2018.

\section{- Clasificación de autor}

En La Opinión se observa que el mismo medio aparece como autor de los géneros periodísticos, nombrando así al medio La Opinión de manera general. Con esta característica aparecen 104 unidades que representan un 60,82\%. Asimismo 35 unidades informativas, que equivalen el 20,47\%, fueron tomadas de medios y agencias periodísticas asociadas (AFP, EFE, Colprensa) y en ellas se ven representadas dichas agencias como autores; además de un $18,71 \%$ (32) donde los periodistas investigadores y redactores reciben sus créditos particulares bien sean periodistas de La Opinión o colaboradores ocasionales. 


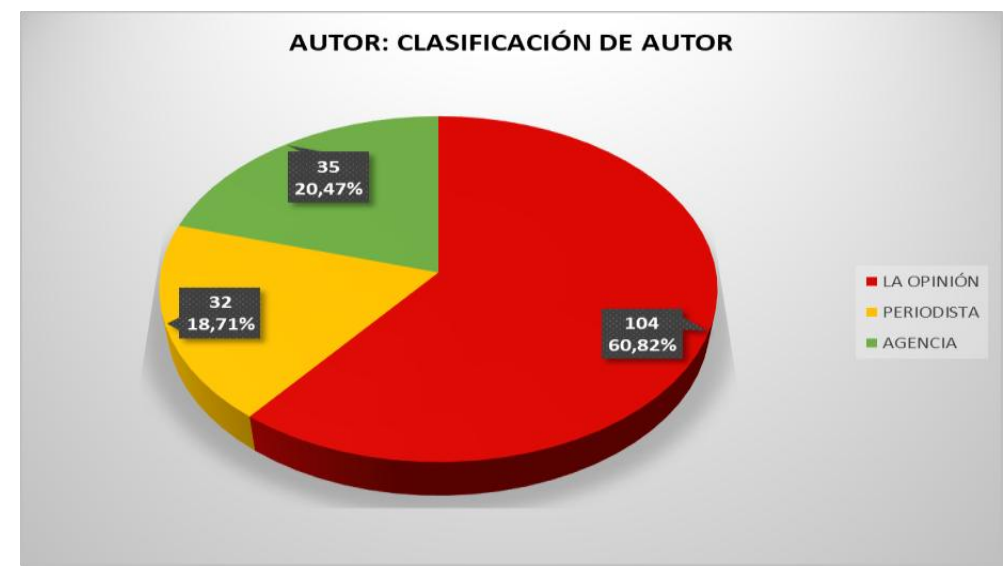

Gráfico 15. Autor: clasificación de autor. Fuente: elaboración propia, 2018.

\section{- Interactividad}

Como en todo cibermedio es de suma importancia la interactividad. Por esta razón, La Opinión abre la posibilidad de interactuar, comentar, discutir y compartir el 100\% de la información publicada a través de las siguientes redes sociales: WhatsApp, Facebook, Twitter, Pinterest y Google Plus, así como también tiene habilitada la opción de realizar comentarios dentro del mismo sitio web.

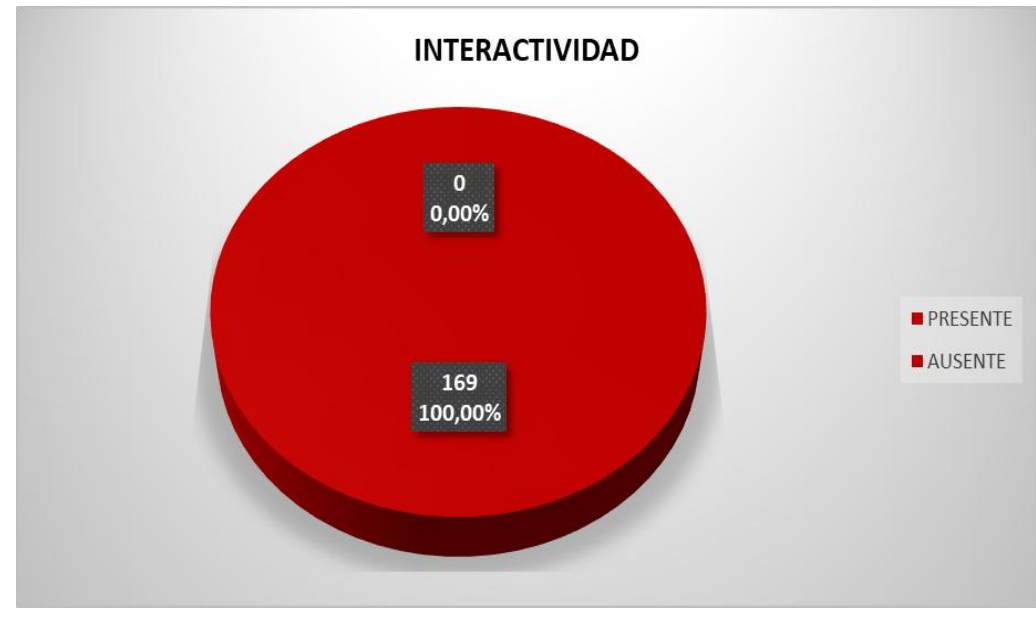

Gráfico 16. Interactividad. Fuente: elaboración propia, 2018. 


\section{Conclusiones}

Con análisis de contenido realizado a 169 géneros periodísticos aparecidos en el cibermedio La Opinión -ubicado en la zona de la frontera colombo-venezolana- sobre el tema de la inmigración venezolana, se puede concluir que emplea adecuadamente los elementos propios del ciberperiodismo, al reunir características como multimedialidad, hipertextualidad e interactividad. Estos aspectos le permiten gestionar y fortalecer su comunidad virtual desde su propia plataforma.

El estudio de la cobertura periodística de la inmigración venezolana también permite concluir que el medio analizado emplea variedad de fuentes para difundir información sobre este tema mediante diferentes géneros periodísticos, entre los cuales destacan la noticia, el reportaje y la crónica. Estos resultados coinciden con que la principal naturaleza del cibermedio sea informativa.

La temática más abordada fue sociedad, donde explican diferentes matices de las vivencias de los venezolanos para cruzar la frontera entre el estado Táchira en Venezuela y el Departamento Norte de Santander en Colombia, así como los temas de salud ante la crisis humanitaria, economía. También aparecen en la agenda de La Opinión el tema económico y los sucesos con varios hechos de violencia donde la figura del inmigrante aparece como víctima y victimario.

En cuanto a los elementos de los géneros periodísticos, La Opinión le otorga preponderancia al elemento sumario, pues está presente en todas las unidades redaccionales, porque explican y ofrecen datos informativos que permiten mejorar la comprensión lectora del texto. Por su parte, los títulos con mayor frecuencia son los informativos, expresivos y actos de habla. Sin embargo, el antetítulo no es empleado en este cibermedio.

Sobre las características del cibermedio, hay que señalar que las etiquetas permiten relacionar los géneros periodísticos en los cibermedios y Venezuela, es la que obtiene el mayor porcentaje, seguido de venezolanos, crisis, Colombia, frontera e inmigrantes. Asimismo, los enlaces internos y externos contribuyen con la comprensión de la situación de la inmigración venezolana.

Las fotografías de los lectores son incorporadas al cibermedio junto a las de los fotógrafos de La Opinión. Esto permite inferir la importancia que le dan a la interactividad, como uno de los rasgos distintivos de los medios digitales. También el uso de infografías, audios y videos otorga mayor visualización al acontecer informativo de este medio de comunicación ubicado en la frontera colombo-venezolana y a partir de este análisis, se concluye que el cibermedio La Opinión tiene un buen uso de los elementos interactivos, multimedia e hipertextual. 


\section{Bibliografía}

Arias, F. (2012). El Proyecto de Investigación. Introducción a la metodología científica (6ta Edición). Caracas: Editorial Episteme. Recuperado de https://bit.ly/2pdpHkd

Baptista Lucio, P.; Fernández Collado, C. y Hernández Sampieri, R. (2014). Metodología de la investigación (6ta Edición). México: McGraw Hill. Recuperado de https://bit.ly/2KulRKo

Bermúdez, G. (2011). Reseña histórica de La Opinión. Crónicas de Cúcuta Blog. (22/10/2011). Recuperado de https://bit.ly/2kijiso

Comisión Europea (2012). Glosario 2.0 sobre migración y asilo. Un instrumento para una mayor comparibilidad. EMN: Luxemburgo. Recuperado de https://bit.ly/2kkud14

De la Vega, I. y Vargas, C. (2014). Emigración intelectual y general en Venezuela:una mirada desde dos fuentes de información. Bitácora, 1, 66-92. Recuperado de https://bit.ly/2kj9paf

Freitez, A. (2011). La emigración desde Venezuela durante la última década. Temas de coyuntura, 63, 11-38. Recuperado de https://bit.ly/1zQfd7k

Fundación Konrad Adenauer (2018). Retos y Oportunidades de la movilidad humana venezolana en la construcción de una política migratoria colombiana. Universidad del Rosario, Observatorio de Venezuela. Recuperado de https://www.kas.de/wf/doc/268691442-4-30.pdf

Hernández, R.; Fernández, C. y Baptista, P. (2014). Metodología de la investigación. México: MacGraw Hill.

Michelena, A. (18/01/2018). Diáspora y preocupación internacional. Revista Zeta. Recuperado de http://revistazeta.net/2018/01/21/diaspora-preocupacion-internacional/

Migración. Ministerio de Relaciones Exteriores (2017). Radiografía de venezolanos en Colombia. Recuperado de http://www.migracioncolombia.gov.co/venezuela/radiografia_web.pdf

Muñíz, C. (2007). Encuadres noticiosos e inmigración: del análisis de los contenidos al estudio de los efectos mediáticos. Tesis para optar al título de Doctor en Comunicación, Universidad de Salamanca. España. Recuperado de https://bit.ly/2mauNPj

Organización Internacional para las Migraciones (OIM). (2006). Derecho Internacional sobre Migración № 7. Glosario sobre Migración. Ginebra, Suiza. Disponible: https://bit.ly/2IUfom0

Robayo, M. C. (2015). Venezolanos en Colombia, un eslabón más de una historia compartida. Recuperado de https://bit.ly/2IMiZTt

Question, Vol. 1, N. ${ }^{\circ}$ 63, julio-septiembre 2019. ISSN 1669-6581 
Sabés, F. (2010). Análisis del tratamiento del fenómeno migratorio en www.elpais.com. Revista Latina de Comunicación Social, 65, 30-44. Recuperado de http://www.revistalatinacs.org/10/art/881_UAB/RLCS_art881.pdf

Salaverría, R. (2016). Ciberperiodismo en Iberoamérica. Barcelona: Universidad de NavarraFundación Telefónica. Recuperado de https://bit.ly/21UscS9

Salaverría, R. (2017). Tipología de los cibermedios periodísticos: bases teóricas para su clasificación. Revista Mediterránea de Comunicación, 8(1), 19-32. Recuperado de https://bit.ly/2mavSql

Suárez, M. (2015). Visión histórica de la frontera Norte de Santander-Táchira. Interacción y Perspectiva, 5(2), julio-diciembre, pp. 221-235. Recuperado de http://revencyt.ula.ve/storage/repo/ArchivoDocumento/iprts/v5n2/art04.pdf

Tapia, M. (2012). Frontera y migración en el norte a partir del análisis de los censos de población. Siglos XIX - XXI. Revista de Geografía Norte Grande, 53, pp 177-198. Recuperado de https://scielo.conicyt.cl/scielo.php?script=sci_arttext\&pid=S071834022012000300011

Tinto, J. (2013). El análisis de contenido como herramienta de utilidad para la realización de una investigación descriptiva. Un ejemplo de aplicación práctca utilizado para conocer las investigaciones realizadas sobre la imagen de marca de España y el efecto de país de Origen. Provincia, 29, enero-junio, pp 135-173 Recuperado de https://www.redalyc.org/pdf/555/55530465007.pdf

Torre, E. (2018). Periodismo, actores sociales y migración: intertextualidad en los discursos periodísticos sobre migración. Convergencia, 77, mayo-agosto, pp. 201-227. Recuperado de http://www.scielo.org.mx/pdf/conver/v25n77/2448-5799-conver-25-77201.pdf 